\title{
Improving HIV Treatment Adherence through a Public Private Partnership in Zambia
}

\author{
Henry Fomundam ${ }^{*}$, Andrew Maranga ${ }^{2}$, Joseph Kamanga ${ }^{3}$, Abraham Tesfay ${ }^{1}$, \\ Tamara Choola ${ }^{4}$, Stephen Nyangu ${ }^{5}$, Anthony Wutoh ${ }^{6}$ \\ ${ }^{1}$ Howard University Pharmaceutical Care and Continuing Education (PACE) Center, Regional Office, Pretoria, \\ South Africa \\ ${ }^{2}$ Howard University Pharmaceutical Care and Continuing Education (PACE) Center, Field Office, Nairobi, Kenya \\ ${ }^{3}$ FHI360 Lusaka, Zambia \\ ${ }^{4}$ Livingstone General Hospital, Livingstone, Zambia \\ ${ }^{5}$ Zambia Health Education and Communications Trust, Livingstone, Zambia \\ ${ }^{6}$ Howard University College of Pharmacy, Washington DC, USA \\ Email: *hfomundam@aol.com
}

Received 4 February 2014; revised 4 March 2014; accepted 11 March 2014

Copyright (C) 2014 by authors and Scientific Research Publishing Inc.

This work is licensed under the Creative Commons Attribution International License (CC BY).

http://creativecommons.org/licenses/by/4.0/

(c) (i) Open Access

\section{Abstract}

Background: Effective ART with low viral loads and absence of STIs significantly reduce chances of sexual transmission of HIV. ART is therefore a key pillar in HIV prevention. Appropriate support is however essential for optimum treatment outcome, patient safety and HIV prevention benefit. The scale-up of ART continues to strain the already overstretched human resources in public facilities, impacts on the quality of care, and contributes to loss to follow-up. Task shifting is therefore a strategy to augment the limited human resources. Methodology: In partnership with the Livingstone General Hospital (LGH) and four private pharmacists, the $\mathrm{COH}$ III Project through Howard University is promoting quality HIV care by engaging the pharmacists in adherence counselling and treatment monitoring. The LGH ART pharmacist allocates consenting stable ART clients to pharmacies based on willingness to be referred and patient preference. Patients are given schedule of visits to pharmacies where the pharmacists provide medication/adherence counselling and monitor side effects. Patients with medication/treatment issues are referred back to the LGH ART clinic for follow-up. Results: Between October 2012 and August 2013, 280 patients were enrolled and followed up by the four pharmacists. $69 \%$ of patients visited the pharmacy at least once, $25 \%$ at least twice and $13 \%$ at least thrice. The 33 client referrals by pharmacists to LGH were related to adverse drug reactions, suspected treatment failure, pregnancy, and treatment monitoring. The

${ }^{*}$ Corresponding author. 
intervention has reduced workload for the ART pharmacist; improved communication of treatment challenges and identification of patients with medication related problems, and reduced travel distances and waiting times. This has resulted in improved adherence and better patient outcomes. Conclusion: Private pharmacists present an opportunity to improve quality of HIV interventions in poor human resource capacity settings. The necessary legal and regulatory framework needs to however be developed to guide the process.

\section{Keywords}

Public-Private Partnership; Adherence Support; Private Pharmacists; Treatment Monitoring; Human Resources Challenge

\section{Introduction}

Zambia bears one of the heaviest burdens of HIV infection in sub-Sahara Africa. The HIV prevalence is estimated around $14 \%$ in the general population aged between 15 and 45 years. Among the population aged 15 - 49 years, the rate among women is estimated at $16 \%$ and that among men at $12 \%$ [1]. Zambia has experienced the effects of high HIV prevalence for more than 20 years. However, there has been indication of a reduction in HIV prevalence in the recent past from $16.6 \%$ in 2001 to $14.3 \%$ in 2007.

The HIV prevalence in Zambia has shown significant regional and geographical variation with border and transit towns having the highest HIV prevalence rates. Livingstone District, with population of about 139,509 [2] has one of the highest HIV prevalence rates of about 22\%; a drop from an estimated 31\% in 2004 [3] among the sexually active population.

Some of the key drivers of the HIV epidemic in Zambia have been identified as multiple and concurrent sexual partnerships, low levels of male circumcision, low rate of condom use, alcohol and drug use, stigma, discrimination and denial, harmful cultural beliefs and practices, gender and sexual violence, low risk perception, high population mobility, high prevalence of sexually transmitted infections, and poverty [4].

The HIV and AIDS services in Zambia began with the provision of HIV counselling and testing. Basic clinical care and support services such as the diagnosis and treatment of tuberculosis, sexually transmitted infections, and malaria were already relatively well-developed [5]. In the last 10 years, Zambia has seen an increase in the number of organisation providing HIV testing and counselling, and referral to centres providing continuum of care including the management of opportunistic infections and antiretroviral therapy (ART) [5].

Antiretroviral therapy, which is primarily provided through the public health sector, has had an impact on the community though reduction in early death, improved lives of those infected persons and been affected by the disease, and contribution to national development [6]. The priority strategy for ART is to ensure universal access to treatment, care and support [7]. However despite progress in increasing access to HIV treatment in the country, system and structural challenges in delivery of ART services still exist and include human resource constrains and poor adherence to treatment [8].

\subsection{The Corridors of Hope III/Roads to a Healthy Future Collaboration}

The Corridors of Hope (COH) III is a USAID/PEPFAR funded project through FHI360 implemented as part of the regional Roads to Healthy Future (ROADS II) programme through a consortium of three Zambian non-governmental organizations [Zambia Health Education and Communications Trust (ZHECT), Zambia Interfaith Networking Group on HIV/AIDS (ZINGO) and Afya Mzuri] and two international NGOs [Development Alternative Incorporated (DAI) and Howard University (HU)]. The project aims to reduce HIV transmission in border and transport corridor communities by targeting high risk populations and the low-risk populations that they interact with. This is done through provision of comprehensive HIV/AIDS prevention strategies and improved linkages and referral networks.

COH III has been working with local partners, the Government of Zambia and other partners in implementing HIV prevention interventions targeting most at risk populations (MARPs) in ten border and transit towns (Livingstone, Kazungula, Solwezi, Kapiri Mposhi, Chipata, Chirundu, Nakonde, Chililabombwe, Sesheke and 
Katete) since 2000. The current COH III project goes beyond the focus on MARPs to include other general population with HIV testing and counselling and referral to continuum of HIV care including ART.

Effective HIV treatment is now considered a major component of prevention interventions. According to the findings of the HIV Prevention Trials Network (HPTN) 052 study, and supported by previous cohort studies, effective ART reduces sexual transmission of HIV [9] [10]. Through partnership with Howard University, the $\mathrm{COH}$ III project is implementing a pilot public-private partnership component in Livingstone, one of $10 \mathrm{COH}$ III project sites in Zambia. Livingstone district is a tourist town, the home of the Victoria Falls in Southern Province of Zambia bordering Zimbabwe with a large network of cross border traders and visitors. Howard University through Ministry of Health, has found willing private sector pharmacists to join and carry out activities in the city of Livingstone aimed at improving the quality of HIV treatment in the community through adherence support.

\subsection{HIV/AIDS Treatment in Zambia}

In Zambia, ART is initiated in patients according to the Zambian National HIV Treatment Guidelines. The recommended adult protocols include first, second and most recently, third line regimens. The first line regimen consists of Tenofovir (TDF), Lamivudine (3TC) and Efavirenz as the core with options for substitution Abacavir (ABC) for Tenofovir (TDF), Emtricitabine (FTC) for Lamivudine (3TC) and Nevirapine (NVP) for Efavirenz (EFV). Tenofovir is the drug of choice and Abacavir is used when there is an established contra-indication to Tenofovir use. For the non-nucleoside reverse transcriptase inhibitors (NNRTI), either Efavirenz or Nevirapine is used according to the patient's profile. Efavirenz is preferred in patients with concurrent or potential TB treatment. Nevirapine is preferred in women of child bearing age without TB. The thymidine analogues (Zidovudine and Stavudine) and protease inhibitors (Ritonavir-boosted Lopinavir) are now reserved for second line therapy [11]. At the Livingstone General Hospital, third line therapy is not yet available and all patients suspected to be failing second line therapy are referred to Lusaka's University Teaching Hospital.

It is important to note that in the Zambian ART care system, health care staff and ART centres are accredited by the Health Professional Council prior to offering HIV care. This accreditation process involves training of health personnel in standardised ART care protocols as well as inspection of health facilities to ensure they meet minimum standards for ART care. However, due to high turnover of trained staff, situations exist where health personnel that are not well versed in ART care provide the service, hence lowering the quality of care [12].

\subsection{Concept of Public Private Partnership in HIV/AIDS}

The HIV epidemic has had significant effects on the public health systems of many sub-Saharan countries where the bulk of the epidemic lies [13]. The epidemic has had an effect on health workforce, increased demand for health services and overstretched the available resources [14]. This has resulted in the increased workload for the available health workers and consequently reduced the quality of care for PLHIV and other diseases [15].

The private sector businesses in sub-Saharan Africa have been greatly affected by the HIV epidemic where it has experienced increased cost of doing business through employee absenteeism and attrition, while at the same time facing a reduction in number of consumers and impoverishing those who remain [16] [17]. Although the response has been slow, the private sector has over time realized the importance of investing in HIV/AIDS programs for the sake of the future of their businesses [18].

In most of sub-Saharan Africa, the private non-government sector continues to play a major role in the provision of health services in the community, complementing the governments' efforts towards access to universal healthcare [19]. With the challenges in the public health system, it is now acknowledged that the private sector holds the key to improvement of the health indicators in developing countries through involvement and partnerships with the public sector. There have been various initiatives that seek to link the public sector to the private sector in an effort the enhance access and quality of health services.

Many public-private partnerships with a health system orientation have emerged in areas where the private partner can combine philanthropic investment with business strategy, expertise and resources, and where this investment guarantees a surplus for the public partner in terms of enhanced health system structures or capacities. This is achieved in service delivery, health workforce support or access to modern technology including health information approaches [20]. The African Comprehensive HIV/AIDS Partnerships (ACHAP), a partnership between the Merck Foundation, the Gates Foundation and the Government of Botswana, played a major 
role in supporting the HIV prevention, treatment and care program in Botswana. The partnership was instrumental in initiating Botswana's antiretroviral (ARV) program in 2001 with Merck providing two ARV drugs (Indinavir and Efavirenz) free of charge. More than 21,000 patients eligible for ART were able to access medicines through this program [21].

The PEPFAR program has had resounding success in HIV prevention, treatment and care and part of this success has been attributed to a large extent in engaging with the private sector in implementation of intervention programs [22]. In HIV prevention, PEPFAR collaborates with the Zambia Tourism Industry through the Livingstone Tourism HIV/AIDS Partnership in workplace and community-based programs to promote social and behavioural change to reduce sexual transmission of HIV in the local and mobile population. In Cote d'Ivoire, PEPFAR partnered with the Société des Caoutchoucs de Grand Bereby (SOGB), a leading rubber company to provide HIV education, prevention of mother-to-child transmission (PMTCT) services, and access to care and treatment services to their employees and the surrounding communities.

In recognition of the role of PPP in enhancing program effectiveness and promoting sustainability, it is vital that all HIV/AIDS intervention programs promote partnerships at all program levels and take advantage of the existing private sector initiatives and resources. The progression of the HIV epidemic, which increasingly requires long-term chronic care, coupled with the evolving nature of the global HIV response from emergency to sustainability, suggests that the private sector may play an expanded role in meeting HIV/AIDS needs in the future [23].

\subsection{The HIV Treatment Program at the Livingstone General Hospital}

As at the end of January 2012, the Livingstone General Hospital had 4200 clients actively accessing ART; although there has been a cumulative number of 8090 enrolled since 2006 The entry point into HIV care for adult patients accessing HIV care at the Livingstone General Hospital (LGH) are the in-patient wards, out-patients referral from health centres managed under Livingstone District Health Management Board, as well as patients from neighbouring districts referred for more specialized care.

Adult patients accessing HIV care at this hospital are followed up in the out-patient ART Clinic. Clients below the age 21 years are enrolled under the Livingstone Paediatric Centre of Excellence for HIV. Each client who has shown stable response to therapy is expected to visit the ART clinic once every three months for their clinical review and pharmacy refill. Clients newly initiated on treatment, those switching regimen, or having complaints with their medication or condition, have their appointment scheduled two to four weeks apart.

On average about 64 adult and 22 paediatric clients visit the ART pharmacy every working day. This number does not include post-exposure (PEP) cases for occupational and non-occupational exposure. A pharmacist and one pharmacist intern are designated to work at the ART pharmacy at any one time (though this is dependent on their availability as interns are not around all year or may have other responsibilities such as attending trainings, mobile outreach services, meetings or covering in other areas within the pharmacy department).

The large numbers of clients make it practically impossible to comprehensively counsel each client and priority is given to those being newly initiated on therapy. The situation is worsened by the lack of adequate space as only one room is allocated to pharmacy and it is used for both dispensing and counselling. Waiting space is also limited as it can only accommodate 18 people at a time and most clients have to stand as they wait in turn. At the beginning of 2012, the Centre for Infectious Disease Research in Zambia (CIDRZ) estimated defaulter rate at the Livingstone General Hospital at 70\%; the highest in the province.

Given the current overwhelming workload of health care workers in the ART clinic, participation of community pharmacists can complement and support the services provided by the ART team in the hospital. Community pharmacists are an underutilized resource that can potentially improve the outcome of patients on HIV treatment by providing patients with ongoing treatment support, medication adherence monitoring and support, and medication reviews, which can increase medication adherence and reduce medication errors. Additionally, patients on ART, often seek advice from the community pharmacists on various health issues. This can attributed to the fact that they are easily assessable, have short waiting time, and have more personalized interaction among other factors [24].

\subsection{The PPP at Livingstone General Hospital}

The Livingstone General Hospital in collaboration with Howard University HIV/AIDS Pharmaceutical Care 
Program through the Corridors of Hope Project partnered with private pharmacies in Livingstone City in a public-private partnership program to increase access to HIV adherence support and treatment literacy and information for patients accessing ART at the hospital.

The benefits of ART in decreasing HIV-related morbidity and mortality, and improving the quality of life of patients on HIV treatment are well documented [25]. However, long-term adherence to antiretroviral regimens remains a challenge, especially where continuous adherence counselling is not offered or is suboptimal. According to the World Health Organization, adherence among patients with chronic diseases averages 50 percent in developed countries and is much lower in developing countries [26]. In order to achieve the goal of antiretroviral therapy (ART), undetectable levels of the virus in the blood, patients are required to maintain more than 90\% - 95\% adherence [27]. Non-adherence to medication regimens can result in disease progression, disease complications, decreased functional abilities, lower quality of life and death. Poor medication adherence is more than a health issue; it has great costs to the economy and Zambian health care system.

\section{Methodology}

\subsection{Project Setting}

The intervention was conducted in the city of Livingstone in Zambia as part of the Corridors of Hope (COH) III project. Livingstone General Hospital is a government-run public hospital serving as a referral hospital for the Southern Province and acting as the ART hub for the district. The facility supports several ART satellite centres that provide ART on an outreach basis.

Howard University, as part of the ROADS II project has been working with private pharmacists in Livingstone as resources for the community in HIV/AIDS prevention, care and treatment interventions. In Livingstone, Howard University designed the public-private partnership (PPP) pilot project to increase access to quality HIV adherence support for stable patients on ART at the LGH through engagement of private pharmacists in adherence support.

\subsection{Pre-Intervention Activities}

There is inadequate information regarding PPP for ART in sub-Saharan Africa. Consequently, guidelines for engagement with pharmaceutical care professionals as health care providers do not exist. Consultative meetings with various stakeholders in the Ministry of Health/National AIDS Council staff at the national, provincial and district level were held during the concept development and pre-implementation phase. This was to obtain the necessary buy-in and also guide the design of the intervention. A three-day update training on ART delivery and programme orientation was conducted for selected participating private pharmacies in the Livingstone Area and the General Hospital staff involved in provision of ART .

Four community pharmacies in the city with qualified pharmacist were selected based on registration status, the type and volume of clients they serve, availability of suitable space for patient counselling, ease of access for patients on ART and their willingness to voluntarily participate in the programme. Stable consenting patients at the LGH were allocated a local participating pharmacy for regular medication adherence counselling and patient education. The patients go back to the hospital for their clinical appointments and medication refills and other services offered by the ART clinic.

\subsection{Data Collection and Analysis}

All participating pharmacies and LGH keep intervention registers of ART clients under care or referred to private pharmacies. The described data below is derived from intervention reports generated from both the Livingstone General Hospital and the participating private pharmacists. The participating pharmacies document all services provided to the patient at every visit, whether scheduled or non-scheduled. Various report/record forms were designed to capture and document the various interventions. The data has been disaggregated by gender, facility, referrals, and reasons for the referrals. Interventions at the various points in the private pharmacy and at the hospital were also reported.

\section{Results}

A total of four private pharmacists were involved in the interventions between October 2012 and September 
2013. During the period under review, a total of 322 (190 female and 132 male) patients were referred for on-going adherence and treatment support at the private pharmacies. The patients were distributed among the four pharmacies; 31\% Link Pharmacy (54 female, 46 male), 23\% HK Pharmacy (52 female, 22 male), 26\% Health Tips Pharmacy (54 female, 30 male), and 20\% LF Moore Chemists (30 female, 34 male). Table 1 summarizes the numbers referred per participating pharmacy disaggregated by gender.

The patients referred to the private pharmacies were given an appointment schedule that was tracked per patient in terms of keeping to the scheduled date. There were a total of 356 pharmacy visits recorded. $76 \%$ of the referred patients attended at least one appointment, $27 \%$ at least two and $7 \%$ at least three. Disaggregated by pharmacy, 34\% (122) visited Link Pharmacy, 23\% (82) HK Pharmacy, 25\% (90) Health Tips Pharmacy, and 17\% (62) LF Moore Chemists.

Table 2 summarizes the reported visits to the pharmacies by the referred ART patients disaggregated by pharmacy and the number of visits by the individual patients.

During the course of the intervention, the private pharmacies referred patients who, in their opinion, presented with conditions or adverse circumstances that required the ART clinicians' attention back to the LGH. A total of 49 referrals were made for various reasons. The reasons for referral included CD4 count measurement, pregnancy, suspected side effects (nausea and vomiting, peripheral neuropathy, anaemia, acute abdominal pain), cotrimoxazole prophylaxis, and suspected treatment failure. Most (11) patients were referred because they had not had a recent CD4 count done as per the recommendations of in the national treatment guidelines.

The disaggregated data by reason for referral is summarized in Table 3 . The table also includes a summary of the pharmacists' recommendations and subsequent actions taken by the clinicians.

\section{Discussion}

Antiretroviral therapy (ART) is a key strategy for USAID/PEPFAR programs in reducing new infections and a cornerstone in reducing AIDS-related deaths and socioeconomic impact of the disease. The World Health Organization (WHO) embarked on the concept of HIV elimination through the use of combination prevention with prevention of mother to child transmission (PMTC) of HIV [28]. Together with UNAIDS, WHO launched Treatment 2.0 to explore modalities of expanding access to ART in a cost effective manner while enhancing life-long retention of patients on ART [29].

There has been massive global expansion of access to HIV treatment. At the end 2012, there were 9.7 million

Table 1. Number of patients on ART linked to private pharmacies for continued adherence and treatment support and prevention counselling in Livingstone $(\mathrm{N}=322)$.

\begin{tabular}{|c|c|c|c|c|c|}
\hline \multirow{2}{*}{ Gender } & \multicolumn{4}{|c|}{ Private Pharmacy } & \multirow{2}{*}{ Total Enrolment } \\
\hline & Link Pharmacy & H.K Pharmacy & Health Tips Pharmacy & L. F Moore chemist & \\
\hline Female & 54 & 52 & 54 & 30 & 190 \\
\hline Male & 46 & 22 & 30 & 34 & 132 \\
\hline Total & $100(31 \%)$ & $74(23 \%)$ & $84(26 \%)$ & $64(20 \%)$ & $322(100 \%)$ \\
\hline
\end{tabular}

Table 2. Number of patients on ART who visited private pharmacies for on-going adherence support and prevention counselling in Livingstone.

\begin{tabular}{|c|c|c|c|c|c|c|}
\hline Facility & $\begin{array}{l}\text { Enrolled } \\
\text { clients }\end{array}$ & $\begin{array}{c}\text { Clients who visited } \\
\text { private pharmacy at } \\
\text { least once }\end{array}$ & $\begin{array}{l}\text { Clients who } \\
\text { visited private } \\
\text { pharmacist at } \\
\text { least twice }\end{array}$ & $\begin{array}{l}\text { Clients who have } \\
\text { visited private } \\
\text { pharmacists at } \\
\text { least three times }\end{array}$ & Total Visits & $\begin{array}{c}\text { Referrals from } \\
\text { private } \\
\text { pharmacists }\end{array}$ \\
\hline Link Pharmacy & 100 & 77 (77\%) & $34(34 \%)$ & $11(11 \%)$ & 122 (34\%) & 32 \\
\hline H. K Pharmacy & 74 & 59 (80\%) & $21(28 \%)$ & $2(3 \%)$ & 82 (23\%) & 13 \\
\hline Health Tips Chemist & 84 & $61(73 \%)$ & $22(26 \%)$ & $7(8 \%)$ & $90(25 \%)$ & 1 \\
\hline L. F Moore Chemist & 64 & $49(76 \%)$ & $10(16 \%)$ & $3(5 \%)$ & $62(17 \%)$ & 3 \\
\hline TOTAL & 322 & $246(76 \%)$ & $87(27 \%)$ & $23(7 \%)$ & 356 (100\%) & 49 \\
\hline
\end{tabular}


Table 3. Number of patients on ART who were referred by private pharmacies to Livingstone General Hospital and reasons for referral $(\mathrm{N}=49)$.

\begin{tabular}{|c|c|c|c|}
\hline Reasons for referral & Recommendation by pharmacist & Action by clinician & \# of clients \\
\hline Newly pregnant & $\begin{array}{l}\text {-Request for HB to be done } \\
\text {-Referred for antenatal clinic }\end{array}$ & $\begin{array}{l}\text {-HB done } \\
\text {-Enrolled in antenatal clinic }\end{array}$ & 5 \\
\hline $\begin{array}{l}\text { Peripheral neuropathy and } \\
\text { lipodystrophy syndrome }\end{array}$ & $\begin{array}{l}\text {-Possible regimen switch from d4T based. } \\
\text {-Do blood sugar \& lipid level tests }\end{array}$ & $\begin{array}{l}\text { Regimen changed to TDF Based after } \\
\text { carrying out ALT/AST } \\
\text { creatinine and urea tests }\end{array}$ & 7 \\
\hline Acute abdominal pain & Switch regimen & Regimen modified & 4 \\
\hline No recent CD4 & Carry out routine lab investigations & $\begin{array}{l}\text { Routine labs requested for, taken and } \\
\text { filed back in patient files }\end{array}$ & 11 \\
\hline $\begin{array}{c}\text { Dizziness, fatigue, heart } \\
\text { palpitations-client on AZT }\end{array}$ & Investigate for anaemia & HB test done & 5 \\
\hline Cardiovascular abnormalities & $\begin{array}{l}\text { Investigate for CCF and assess renal } \\
\text { function-client on TDF }\end{array}$ & $\begin{array}{l}\text { Referred to UNIVERSITY } \\
\text { Teaching hospital_LUSAKA }\end{array}$ & 1 \\
\hline Suspected treatment failure & Viral load-regimen switch & $\begin{array}{l}\text { 1-Viral load to be done from Lusaka. } \\
\text { 2-Regimen switched }\end{array}$ & 2 \\
\hline $\begin{array}{l}\text { Client eligible for Co-trimoxazole } \\
\text { prophylaxis but not prescribed }\end{array}$ & Co-trimoxazole refill & $\begin{array}{l}\text { Cotrimoxazole prescribed } \\
\text { and supplied }\end{array}$ & 5 \\
\hline Nausea and vomiting & To see clinician & $\begin{array}{l}\text { Symptoms resolved by the time the } \\
\text { client decided to visit the hospital }\end{array}$ & 9 \\
\hline Total Referrals & & & 49 \\
\hline
\end{tabular}

N.B—some clients were referred with more than one of the above reason.

PLHIV receiving ART in low- and middle-income countries. In sub-Saharan Africa, 7.5 million PLHIV were accessing ART during this period; a major gain from 50,000 in 2002 [30]. Despite the immense gains, there are still challenges that exist in meeting the huge demand for HIV prevention, care and treatment services created and ensuring that the quality of these services meets the minimum requirements. These challenges are related to, among others, the severe shortage of human resources for health, ensuring consistent supply of drugs and commodities, health infrastructure constrains as well as social issues relating to stigma and discrimination. Successful scaling up-antiretroviral treatment in southern African countries with human resource constraints entails distribution of tasks involved in ART care continuum across human and professional potential [31].

The rapid scale-up of ART and the great demand for the service has created great pressure on the available health care personnel who have to provide care and support to the patients without commensurate increase in the number of personnel [32]. This is in addition to providing services to other non-HIV patients especially in the era of integrated services. This inadvertently causes poor quality of services and increases patient dissatisfaction leading to poor adherence and loss to follow up.

\subsection{Acceptability and Feasibility of Services}

Private Pharmacies and other drug outlets have been documented to be major and trusted source of health information and services in the community particularly in the rural and peri-urban areas. This is attributed to close proximity to the community, perceived better quality of services compared to the public health facilities, and friendlier and faster services [33]. In this intervention, 322 individuals agreed to receive their regular ART services from the private pharmacies; an indication of acceptability of the services offered by the pharmacists.

Pharmacists in the private sector are also highly trained health professionals. With the necessary capacity building and regular skills and knowledge upgrade similar to that received by their counterparts in the public sector, these health personnel can play a major role in improving quality of HIV treatment, care and support services.

\subsection{Decongesting the Public Health Facilities}

The shortage of health workers in sub Saharan Africa has been a major hurdle in ensuring universal access to 
healthcare including HIV services [34] [35]. This has been attributed to several factors including few numbers trained in the countries, uneven geographical distribution, immigration of health workers to higher income countries with better remuneration and conditions of service, increased demand for health services as a result of the HIV epidemic and the scale-up of ART [36].

ART Pharmacy services at the LGH are severely strained by the high patient numbers and the lack of adequate personnel. The 356 patient visits that were recorded during the intervention period represent a significant saving in terms of time for the ART pharmacist who can then use the time concentrate efforts on patients who need better adherence counselling and treatment monitoring.

\subsection{Improved Adherence}

In order to optimize the benefits of ART in HIV prevention and maximize treatment outcome, a high degree of adherence to treatment is necessary [37]. With the high patient numbers and low levels of staffing, health workers in the public facilities have little time per patient and can therefore not provide adequate attention to each patient. With the interaction with the patients during the visits (356 patient encounters during the period), the private pharmacists provided on-going adherence support and monitoring to the patients thereby increasing the chances of optimal adherence. This may be done through counselling and established adherence monitoring measures including patient assessment and pill counts [38].

\subsection{Enhanced Treatment Monitoring}

Part of the goals of ART is to restore immune function, achieve maximal and durable suppression of viral load, and prevent opportunistic infections. To ensure this, appropriate treatment monitoring through clinical assessment, periodic CD4 count and, where available, viral load measures is essential [39]. During the course of the intervention, the participating private pharmacists referred patients for 49 events related to treatment monitoring that, in their opinion, required the input of a clinician.

These events included need for CD4 count (11), suspected treatment failure (2), and cotrimoxazole prophylaxis not provided (5). This demonstrates the unique opportunity presented by private pharmacists as an important resource in HIV treatment support and monitoring.

\subsection{Patient Safety and Improved Detection and Management of Adverse Effects}

Side effects of antiretroviral drugs are diverse, have been widely documented, may be short or long term, and may appear at various stages of treatment [40]. These, in addition to the large number of drugs used in the management of HIV and its associated co-morbidities (through drug interactions), presents a major challenge in HIV management and potentially delays initiation of treatment and affects adherence to treatment [41]. Prevention, early detection and management of side effects are therefore critical to maximizing treatment and ensuring that patients adhere to treatment.

In the LGH intervention, pharmacists reported 26 suspected adverse events that ranged from gastrointestinal disturbances to peripheral neuropathy and cardiovascular abnormalities. These side effects were managed by the clinicians through supportive measures, change or modification in drug regimens and referral for specialized care.

\section{Conclusions}

There is great potential for PPP initiatives in improving quality of health care for ART clients. From the experiences of the partnership between Livingstone General Hospital and the private pharmacies in Livingstone, the private sector is willing to make a contribution to interventions of public health importance. There is also great potential in promoting HIV prevention and adherence among patients on ART through collaboration with healthcare providers in the private sector. Although the calibre of health workers in the private sector is diverse, they all can be utilized in public health interventions at the level at which their skills and competencies allow. Additionally, it may be necessary to improve or upgrade their skills and knowledge, based on a skill and capacity assessment, to effectively deliver on this mandate.

It is however important that such interventions are in line with the legal framework regulating the operations of private health facilities to ensure quality of services and that the safety of patients is safeguarded. 


\section{Acknowledgements}

This article is made possible by the support of the American People through the United States Agency for International Development (USAID) and the Corridors of Hope (COH) III project. The contents of this article are the sole responsibility of the authors and do not necessarily reflect the views of USAID, the United States Government, Howard University, FHI360 or ZHECT.

\section{References}

[1] Central Statistics Office, Ministry of Health, Tropical Diseases Research Centre, University of Zambia and Macro International Inc. (2009) Zambia Demographic and Health Survey, 2007. CSO and Macro International Inc., Calverton.

[2] Central Statistics Office (2012) Zambia 2010 Census of Population and Housing. Population Summary Report.

[3] National HIV/AIDS/STI/TB Council (Zambia) (2004) The HIV/AIDS Epidemic in Zambia.

[4] National HIV/AIDs/STI/TB Council (Zambia) (2009) National Strategy for the Prevention of HIV and STIs.

[5] Ministry of Health (Zambia), Central Statistical Office (Zambia) and ORC Macro (2006) Zambia HIV/AIDS Service Provision Assessment Survey 2005. Ministry of Health, Central Statistical Office, and ORC Macro, Calverton.

[6] National HIV/AIDS/STI/TB Council (Zambia) (2009) National Strategy for the Prevention of HIV and STIs.

[7] National HIV/AIDS/STI/TB Council (Zambia) (2010) National AIDS Strategic Framework 2011-2015.

[8] National HIV/AIDS/STI/TB Council (Zambia) (2011) Report of the 2011 National HIV Prevention Convention $15^{\text {th }}-17^{\text {th }}$ November 2011.

[9] Donnell, D., Baeten, J.M., Kiarie, J., Thomas, K.K., Stevens, W., Cohen, C.R., McIntyre, J., Lingappa, J.R. and Celum, C. (2010) Heterosexual HIV-1 Transmission after Initiation of Antiretroviral Therapy: A Prospective Cohort Analysis. Lancet, 375, 2092-2098.

[10] Cohen, M.S., Chen, Y.Q., McCauley, M., et al. (2011) Prevention of HIV-1 Infection with Early Antiretroviral Therapy. New England Journal of Medicine, 365, 493-505. http://www.nejm.org/doi/pdf/10.1056/NEJMoa1105243

[11] Ministry of Health (Zambia) (2010) Adult and Adolescent Antiretroviral Therapy Protocols 2010.

[12] Hanefeld, J. and Musheke, M. (2009) What Impact Do Global Health Initiatives Have on Human Resources for Antiretroviral Treatment Roll-Out? A Qualitative Policy Analysis of Implementation Processes in Zambia. Human Resources for Health, 7, 8. http://www.human-resources-health.com/content/pdf/1478-4491-7-8.pdf

[13] United Nations (2004) The Impact on the Health Sector in Impact of AIDS. Department of Economic and Social Affairs Population Division. http://www.un.org/esa/population/publications/AIDSimpact/90_CHAP_VII.pdf

[14] Tawfik, L. and Kinoti, S.N. (2006) The Impact of HIV/AIDS on the Health Workforce in Developing Countries. Background Paper Prepared for The World Health Report 2006, Working Together for Health. http://www.who.int/hrh/documents/Impact of HIV.pdf

[15] World Health Organization (2004) Standards for quality HIV Care: A Tool for Quality Assessment, Improvement, and Accreditation. Report of a WHO Consultation Meeting on the Accreditation of Health Service Facilities for HIV Care. Geneva.

[16] Rosen, S., Vincent, J.R., MacLeod, W., Fox, M., Thea, D.M. and Simon, J.L. (2004) The Cost of HIV/AIDS to Businesses in Southern Africa. AIDS, 18, 317-324. http://dx.doi.org/10.1097/00002030-200401230-00023

[17] Ramiah, I. and Reich, M.R. (2006) Building Effective Public-Private Partnerships: Experiences and Lessons from the African Comprehensive HIV/AIDS Partnerships (ACHAP). Social Science \& Medicine, 63, 397-408. http://dx.doi.org/10.1016/j.socscimed.2006.01.007

[18] The Commission on HIV/AIDS and Governance in Africa (2006) HIV/AIDS and the Private Sector in Africa: Impact and Responses. United Nations Economic Commission for Africa. http://www.bu.edu/cghd/files/2010/12/Rosen-S-CHGA-Final-Report-25-February-20061.pdf

[19] Center for Global Development (2009) Partnerships with the Private Sector in Health. What the International Community Can Do to Strengthen Health Systems in Developing Countries. Final Report of the Private Sector Advisory Facility Working Group. http://www.cgdev.org/files/1423350_file_CGD_PSAF_Report_web.pdf

[20] Joint United Nations Programme on HIV/AIDS (2009) HIV-Related Public-Private Partnerships and Health Systems Strengthening. http://data.unaids.org/pub/Report/2009/jc1721_publicprivatepartnerships_en.pdf

[21] Ramiah, I. and Reich, M.R. (2005) Public-Private Partnerships and Antiretroviral Drugs for HIV/AIDS: Lessons from Botswana. Health Affairs, 24, 545-551. http://dx.doi.org/10.1377/hlthaff.24.2.545

[22] Sturchio, J.L. and Cohen, G.M. (2012) PEPFAR's Public-Private Partnerships Achieved Ambitious Goals, from Im- 
proving Labs to Strengthening Supply Chains. Health Affairs, 31, 1450-1458.

http://content.healthaffairs.org/content/31/7/1450.full.pdf+html http://dx.doi.org/10.1377/hlthaff.2012.0585

[23] Sulzbach, S., De, S. and Wang, W. (2011) The Private Sector Role in HIV/AIDS in the Context of an Expanded Global Response: Expenditure Trends in Five Sub-Saharan African Countries. Health Policy and Planning, 26, i72-i84. http://heapol.oxfordjournals.org/content/26/suppl 1/i72.full.pdf http://dx.doi.org/10.1093/heapol/czr031

[24] Williams, H.A. and Jones, C.O. (2004) A Critical Review of Behavioral Issues Related to Malaria Control in Sub-Saharan Africa: What Contributions Have Social Scientists Made? Social Science and Medicine, 59, 501-523. http://dx.doi.org/10.1016/j.socscimed.2003.11.010

[25] Siegfried, N., Uthman, O.A. and Rutherford, G.W. (2010) Optimal Time for Initiation of Antiretroviral Therapy in Asymptomatic, HIV-Infected, Treatment-Naive Adults (Review). Cochrane Database of Systematic Reviews Issue 3, Article No. CD008272.

http://www.aidstruth.org/sites/aidstruth.org/files/Cochrane\%20review\%200ptimal\%20time\%20for\%20ART\%20initiat ion\%202010.pdf

[26] World Health Organization (2003) Adherence to Long-Term Therapies Evidence for Action. http://www.who.int/chp/knowledge/publications/adherence_full_report.pdf

[27] Hardon, A., Davey, S., Gerrits, T., Hodgkin, C., Irunde, H., Kgatlwane, J., Kinsman, J., Nakiyemba, A. and Laing, R. (2006) From Access to Adherence: The Challenges of Antiretroviral Treatment-Studies from Botswana, Tanzania and Uganda. http://arcHIVes.who.int/prduc2004/Book/MULTICOUNTRY.pdf

[28] World Health Organization (2012) Antiretroviral Treatment as Prevention (TASP) of HIV and TB. Programmatic Update. http://whqlibdoc.who.int/hq/2012/WHO_HIV_2012.12_eng.pdf

[29] World Health Organization/Joint United Nations Programme on HIV/AIDS (2011) The Treatment 2.0 Framework for Action: Catalysing. The Next Phase of Treatment, Are and Support.

http://whqlibdoc.who.int/publications/2011/9789241501934_eng.pdf

[30] World Health Organization (2013) Global Update on HIV Treatment 2013. Results, Impacts and Opportunities. http://apps.who.int/iris/bitstream/10665/85326/1/9789241505734_eng.pdf

[31] Van Damme, W., Kober, K. and Kegal, G. (2008) Scaling-Up Antiretroviral Treatment in Southern African Countries with Human Resource Shortage. How Will Health System Adapt. Social Science and Medicine, 66, 2108-2121. http://dx.doi.org/10.1016/j.socscimed.2008.01.043

[32] Assefa, Y., Jerene, D., Lulseged, S., Ooms, G. and Van Damme, W. (2009) Rapid Scale-Up of Antiretroviral Treatment in Ethiopia: Successes and System-Wide Effects. PLoS Medicine, 6, e1000056.

http://www.plosmedicine.org/article/fetchObject.action?uri=info\%3Adoi\%2F10.1371\%2Fjournal.pmed.1000056\&repr esentation=PDF http://dx.doi.org/10.1371/journal.pmed.1000056

[33] Fomundam, H., Tesfay, A., Maranga, A., Chanetsa, L., Muzoola, V. and Oyaro, F. (2012) Identifying Treatment and Healthcare Seeking Behavior as a Means of Early HIV/AIDS Intervention in Africa. World Journal of AIDS, 2, 165173. http://dx.doi.org/10.4236/wja.2012.23022

[34] World Health Organization (2006) The World Health Report 2006: Working Together for Health. http://www.who.int/whr/2006/whr06 en.pdf

[35] Mæstad, O. (2006) Human Resources for Health in Tanzania: Challenges, Policy Options and Knowledge Gaps. CMI Report. http://www.cmi.no/publications/file/2175-human-resources-for-health-in-tanzania-challenges.pdf

[36] Bärnighausen, T., Bloom, D.E. and Humair, S. (2007) Human Resources for Treating HIV/AIDS: Needs, Capacities, and Gaps. AIDS Patient Care and STDS, 21, 799-812. http://dx.doi.org/10.1089/apc.2007.0193

[37] World Health Organization (2012) Programmatic Update. Antiretroviral Treatment as Prevention (TASP) of HIV and TB. http://whqlibdoc.who.int/hq/2012/WHO_HIV_2012.12_eng.pdf

[38] McMahon, J.H., Jordan, M.R., Kelley, K., Bertagnolio, S., Hong, S.Y., Wanke, C.A., Lewin, S.R. and Elliott, J.H. (2011) Pharmacy Adherence Measures to Assess Adherence to Antiretroviral Therapy: Review of the Literature and Implications for Treatment Monitoring. Clinical Infectious Diseases, 52, 493-506.

http://cid.oxfordjournals.org/content/52/4/493.full.pdf+html http://dx.doi.org/10.1093/cid/ciq167

[39] Mermin, J., Ekwaru, J.P., Were, W., Degerman, R., Bunnell, R., Kaharuza, F., Downing, R., Coutinho, A., Solberg, P., Alexander, L.N., Tappero, J., Campbell, J. and Moore, D.M. (2011) Utility of Routine Viral Load, CD4 Cell Count, and Clinical Monitoring among Adults with HIV Receiving Antiretroviral Therapy in Uganda: Randomised Trial. British Medical Journal, 343, d6792.

http://www.bmj.com/highwire/filestream/536788/field_highwire_article_pdf/0/bmj.d6792

[40] Hawkins, T. (2010) Understanding and Managing the Adverse Effects of Antiretroviral Therapy. Antiviral Research, 85, 201-209. http://dx.doi.org/10.1016/j.antiviral.2009.10.016

[41] Johnson, M.O., Dilworth, S.E., Taylor, J.M. and Neilands, T.B. (2011) Improving Coping Skills for Self-Management 
of Treatment Side Effects Can Reduce Antiretroviral Medication Non-Adherence among People Living with HIV. Annals of Behavioral Medicine, 41, 83-91.

http://download.springer.com/static/pdf/114/art\%253A10.1007\%252Fs12160-010-9230-4.pdf?auth66=1380024506_24 8edb32e8347ef750337c0d1ffad56c\&ext=.pdf http://dx.doi.org/10.1007/s12160-010-9230-4 